\title{
Eğitsel/Mesleki Hedef Belirleme Sürecinde Yaratıcı Drama ve Grupla Danışmanın Etkililiğinin İncelenmesi
}

\author{
Derya Atalan Ergin ${ }^{1}$
}

Nejat Akfirat ${ }^{2}$

\begin{abstract}
$\ddot{O} z$ et
Meslek seçimi; mesleki olgunluk, ilgi, yetenek, özyeterlik algısı gibi pekçok kavramla ilişkili değerlendirilebilir. Çocukluk ve ergenlik dönemi kimlik gelişimi açısından kritiktir ve bu dönemlerde öz kavramı belirginleşir. Öz kavramının belirginleşmesi ile birlikte bireyin meslek seçim sürecinde de yol alması beklenmektedir. Ancak Türkiye'de yapılan çalışmalar bireyin meslek seçim sürecinde beklenen düzeyde olmadiğını göstermektedir. Bu çalışmada amaç ortaokul yedinci sınıfa devam eden ögrencilerin meslek kararı verme, ĕgitsel/mesleki hedef belirleme karar süreçlerinde yaratıcı drama ve grup rehberliği yöntemlerinin etkililiğinin değerlendirilmesidir. Bu amaçla Ankara ili Mamak ilçesindeki bir ilköğretim okuluna devam eden öğrencilerden seçkisiz örnekleme ile yaratıcı drama ( $k \imath z=10$, erkek $n=5)$, grupla danışma (klz $n=7$, erkek $n=8)$ grubu ve kontrol grubu ( $k ı z n=7$, erkek $n=8$ ) oluşturulmuştur. Yaratıcı drama ve grupla danışma gruplarına ĕgitsel/mesleki rehberlik çalışmaları yapılmış, kontrol grubu bekleme listesine alınmıştır. Uygulanan programların etkililiğinin değerlendirilmesi amacıyla "Piers- Harris'in Çocuklarda Öz Kavramı Ölçeği”, "Meslek Kararı Verme Yetkinlik Ölçeği ” ve araştırmacı tarafindan hazırlanan açık uçlu sorulardan oluşan anket formu kullanılmıştır. Nicel veriler Wilcoxon İ̧̧aretli Siralar Testi, nitel veriler ise içerik analizi yöntemleri ile değerlendirilmiştir. Araştırmanın sonuçlarına bakıldı̆̆ında öğrencilerin eğitsel/mesleki hedef belirlemede kendilerini yetkin görme düzeylerinin artırmada yaratıcı drama ve grup rehberliği oturumlarının etkili olduğu, ancak öz kavramlarını değiştirmede yaratıcı drama ve grup rehberliği uygulamalarının etkili olmadı̆̆ görü̈lmüştür.
\end{abstract}

Anahtar sözcükler: Yaratıcı drama, mesleki hedef belirleme, eğitsel hedef belirleme, grupla danışma

\section{The Implementation of Creative Drama and Group Counseling Programs in the Process of Educational/Vocational Goal Setting}

\begin{abstract}
Choosing a career can be evaluated related to many concepts such as vocational maturity, interests, skills, and self efficacy. Childhood and adolescence are critical to the development of identity and self-concept is evident in these periods. Within the clarification of self-concept occupation, it is expected to take the lead the individual in the period of choosing profession. However, the studies in Turkey show that choosing a profession is not expected level of the individual. This study aims to decide the profession of secondary school students attending seventh grade, educational / vocational goal setting in decision making processes to evaluate the effectiveness of group counseling methods and creative drama. For this purpose, creative drama with random sampling of students attending an elementary school in Ankara province Mamak district (girls $n=10$, male $n=5)$, group counseling (female $n=7$, male $n=8)$ and control group $($ girls $n=7$ male $n=8)$
\end{abstract}

1 Öğretmen, Milli Eğitim Bakanlığı, deryaatalan@gmail.com

2 Dr., Milli Eğitim Bakanlığı, nejatakfirat@gmail.com 
is formed. Creative drama and educational advisory group to group / vocational guidance work has been done, has been on a waiting list control group. In order to evaluate the effectiveness of programs. "Piers Harris' Self-Concept Scale for Children “, " Career Decision Making Self Efficacy Scale “ and a questionnaire was used consisting of open-ended questions prepared by the researcher. Considering the results of the research, educational / in determining career goals of the students is to increase the level of their competent to be effective creative drama and group counseling sessions, however creative drama in changing their selfconcept and has been shown to be effective group counseling practice.

Keywords: Creative drama, vocational goal setting, educational goal setting, group counseling

\section{Giriş}

Eğitimin temel amacı, kendini tanıyan ve gerçekleştiren bireyler yetiştirmektir. Bu temel amacın altında pek çok alt amaç sıralanabilirken, bireyin mesleki olgunluğa erişmesi ve bu alanda hedef belirleyebilmesinin bu alt amaçların en önemlilerinden biri olduğu söylenebilir. Eğitsel ve mesleki gelişim, kuramlarda bir süreç olarak incelenmektedir. Çoğunlukla okul öncesi dönemle ele alınmaya başlanan bu süreç bir mesleğin kazanılmış olacağının öngörüldüğü yetişkinlik dönemine kadar sürmekte hatta kimi kuramlarda daha sonraki dönemlerde de devam etmektedir. Evrelerle ilerlemenin vurgulandığ kuramlarda, her evrede beklenen gelişim görevlerinin başarıyla tamamlanması ile birey mesleki olgunluğa erişmektedir. Mesleki olgunluk kazanmak Bacanlı (1995) tarafından; her bir mesleki gelişim basamağında karşılaşılan bir takım tipik ve gerekli problem çözme yaşantıları (mesleki gelişim görevleri) ile karşılaşmak, bir sonraki basamakta karşılaşılacak gelişim görevlerine hazır olabilmek için bu temel becerileri edinmek olarak tanımlanmaktadır. Bu da bireyin kişilik, ilgi ve yeteneklerine uygun bir meslek seçimi yapmasına olanak sağlamaktadır. Çalışmalar, bireyin meslek kararında mesleğe yönelik olarak duyduğu ilgi, sahip olduğu değerler ve elde edeceği doyum gibi faktörlerin yanı sıra kişisel özelliklerinin de etkili olduğunu göstermektedir (Tokar, Fisher ve Subich, 1998).

Çocuğun ve ergenin gelişim özellikleri ve bilişsel yapısına uygun olarak, bireye ve çevresine ait birçok etmenin etkileşimi ile oluşan mesleki gelişim sürecinin beş aşamadan oluştuğu ifade edilmektedir (Özgüven, 2000: 151-152):

- Uyanış ve Farkında Olma: Okul öncesi dönemden ilkokul sonlarına kadar süren dönemdir. Dönemin başlarında çocuk, çevresindeki meslekleri fark ederek bireylerin farklı mesleklere sahip olduklarını anlar. Dönemin sonlarında ise çocuk kendisi ile diğer insanlar arasında ilgiler, yetenekler, amaçlar ve motivasyon yönünden farklılıkların ve benzerliklerin farkına varmaya başlar.

- Meslekleri Keşfetme ve Araştırma: İlköğretim ikinci kademeden başlayarak birçok kişi için ömür boyu devam eden bu süreçte meslekler ve bireyler daha ayrıntılı olarak değerlendirilerek, kişi özellikleri ile mesleklerin uyumu değerlendirilmeye başlanır.

- Karar Verme: Lise dönemini kapsayan bu süreçte birey, kendi özellikleri ile mesleklerin özelliklerini eşleştirmeye ve kendisini için meslek fikrini belirginleştirmeye başlar.

- Hazırlık: Mesleğe hazırlık döneminde birey seçeceği meslekle ilgili bilgi ve becerilerini geliştirir. Meslek alanında iş araştırmaya başlar ve hazırlık dönemini uzatarak sürdürebilir.

- İşe Yerleşme: Bu dönemde birey, öğrendiği bilgi ve becerileri uygulamaya başlar. İşe yerleşme dönemi gelişimin devam ettiği, bilgi ve beceri birikiminin gelişerek ilerlediği dönemdir.

Meslek seçimini inceleyen kuramların iki yaklaşım çerçevesinde şekillendiği belirtilebilir. İlk çerçevede meslek seçimini bir süreç olarak değerlendiren, ikinci çerçevede ise meslek ile bireyin özelliklerinin ilişkisini vurgulayan kuramlar bulunmaktadır. 
Meslek seçiminin bir süreç olduğunu ilk vurgulayan kuramcılar Ginzberg, Ginsburg, Axelrad ve Herma (1951)'dır. Kuramda, bireyin mesleğini bir anda verilen bir karar sonucunda değil, hayat boyunca oluşan ve gelişen ve büyük ölçüde geri dönülemez olan davranış örüntüleri yoluyla seçtiği belirtilmektedir (Kuzgun, 2002). Evreler; hayal dönemi, geçici seçim dönemi ve gerçekçi seçim dönem olarak adlandırılmaktadır. Bir diğer kuramda Super, mesleki gelişimini hayat boyu ele almaktadır. Benliğin oluştuğu ve meslek seçiminde ilerlemenin olduğu dönemler; büyüme, araştırma, yerleşme, koruma ve çöküş evreleri olarak adlandırılmaktadır.

“Özellik-Faktör Kuramı”, mesleki gelişiminin bireyin kişilik özellikleri ile ilgili olarak ele alındığ1 ikinci çerçevededir. Bu çerçevenin temelinde yer alan ve Parsons'ın ilk kurama isim vererek bu alanın babası olarak anılmasını sağlayan (Herr, 2001) özellik faktör kuramında Parsons, mesleklerin bazı temel özellikleri ile bireylerin özelliklerini eşleştirmeyi amaçlamıştır. Aynı biçimde Holland tipoloji kuramında, kişilik özelliklerini gerçekçi, araştırıc1, sosyal, gelenekçi, girişimci, sanatçı olarak 6 grupta toplamakta ve her kişilik özelliğine uygun meslek gruplarını da ele almaktadır. İnsanların, kişilik özellikleri bakımından gruplanabileceği, bu grupların niteliklerine uygun çevrelerde mutlu ve başarılı olabileceklerini belirtmiştir (Kuzgun, 2009). Bu başlık altındaki kuramları destekleyen çalışmasında Oğuz (2008), mesleki olgunluğun en önemli yordayıcısının öz yeterlik olduğunu bulgulamıştır. Whiston ve Keller (2004) de çalışmasında öğrencilerin mesleki olgunluk puanları ile özyeterlik puanları arasında anlamlı bir ilişki olduğunu belirtmektedir. Bu bulgular bireyin öz kavramı ve meslek seçimi arasında bir ilişkiyi destekler görülmektedir.

Mesleki gelişim kuramları incelendiğinde 12-15 yaş arasındaki kişilerin bu dönemde kendini tanıma, ilgi ve yeteneklerini keşfetme, meslekleri keşfetme ve rol denemeleri yapma becerilerini geliştirdikleri görülmektedir. Başka bir deyişle, kişi kendi ilgi ve yetenekleri ile mesleklerin ilişkisini kurmakta, meslek incelemeleri ve sınama gibi etkinlikleri sürdürmektedir. Ginzberg'in kuramına göre deneme, Super'ın kuramına göre ise araştırma döneminde olan birey, gelişimsel olarak ise ergenlik çağındadır. Ergenlikte bilişsel özelliklerin ve soyut düşünme yeteneğinin geliştiği ve bireyin kimliğini oluşturma sürecine girdiği bilinmektedir. Özellikleri sıralanmış bu birey ülkemizde ortaokul döneminde bulunmaktadır. Ortaokul sonrası gireceği sınavlarla yerleşeceği üst eğitim kurumu belirlenmekte ve bu da mesleğe adımda önemli bir rol oynamaktadır. Birey daha değerlendirme aşamasında iken bir seçim yapmaya zorlanmakta ve üst eğitim kurumunu belirlemesi gereken bir aşamaya gelmektedir. Ortaokulun sonuna kadar hedef belirlemeden gelen ve üst eğitim kurumları ile meslek seçimi konusunda yeterli farkındalığı kazanmamış birey bu seçim sırasında bocalamakta ya da rastgele seçimler yapmaktadır. Akbalık (1991) çalışmasında ortaokul 3. sınıf öğrencilerinin neredeyse yarıya yakınının meslek seçme ihtiyacı içinde olmadıklarını ifade etmektedir. Ayrıca ülkemizde özellikle meslek edindirme amaçlı liselere devam eden öğrencilerle yapılmış çalışmalarda öğrencilerin mesleki olgunluk düzeyleri düşük bulunmuştur (Köküsoy, 2008; Özgan, 2006). Mesleki olgunluk, ilgi ve yeteneklere uygun bir meslek seçimi, doğru öz kavramı ve yeterliği algısı ile ilişkilidir. Üst eğitim kurumuna yerleşmiş ve meslek seçim sürecinde büyük adımı atmış bireyin mesleki olgunluğunun düşük bulgulanması, ortaokul döneminde bu alanda çalış1lması gerekliliğini gözler önüne sermektedir. Yapılan çalışmalar da uygulanan grup rehberliği programlarının öğrencilerin mesleki olgunluk düzeyini artırmada (Ayas, Deniz ve Kağan, 2010; Bacanl1, 1995,2005; Bal, 1998; Evren, 1999, 2005; İşgör ve Sezer, 2008; Makro ve Savickas, 1998; Uskaner, 1999) ve meslek kararı verme sürecinde etkili olduğu bulgulanmıştır (Bozgeyikli,2005; Kırdök, 2006; Symes, 1998). Ayrıca Zeren (1999) ve Çoban (2005) çalışmalarında, mesleki rehberlik yardımı alma ile mesleki olgunluk arasında anlamlı bir ilişkinin olduğu sonucuna ulaşmışlardır. Tüm bu nedenlerle öğrencilerin eğitsel/mesleki hedef belirlemenin önemine ilişkin farkındalık kazanmaları, bu süreçte etkili olan değişkenler, meslekler ve üst eğitim kurumları hakkında fikir sahibi olmaları önemli görülmektedir. 
Meslek seçimi ve kişinin özelliklerinin ilişkilendirilmeye çalışıldığı ilk dönemlerde Parson tarafından "Mesleki Rehberlik" olarak kullanılan ve "gençlere kendi kapasitelerine uygun meslek seçmeleri için yapılan yardımlar” olarak tanımlanan (Isaacson ve Brown, 1997) çalışmalar son zamanlarda uygulamada ve alanyazında yaşam boyu gelişim kuramlarını destekler niteliğe dönüşerek kariyer rehberliği ve psikolojik danışmanlık olarak anılmaya ve daha fazla yaşam boyu verilen bir hizmet olarak ele alınmaya başlamıştır (Herr ve Cramer, 1996). $\mathrm{Bu}$ haliyle pek çok hizmet alanının kariyer gelişimi ile ilişkili görülmesine karşın, eğitim kurumları bünyesinde mesleki rehberlik etkinliklerini -buna yönelik farkındalık eğitimleri, hedef belirleme çalışmaları vb.- sınıf öğretmenleri ile rehberlik birimleri yürütmektedir.

Çalışmanın uygulama sürecinde iki müdahale yöntemi kullanılacaktır: yaratıcı drama ve grup rehberliği. Yaratıcı drama, kazandırılmak istenen bilginin çoğu zaman doğrudan verilmemesi, öğreneni zihnen ve bedenen sürekli aktif durumda tutarak öğrenmenin tam olarak gerçekleşmesini amaçlaması nedeniyle özellikle son zamanlarda dikkat çeken yaklaşımlar arasındadır. Adıgüzel (2001) yaratıcı dramanın amaçlarını şöyle belirtmektedir: " Çocukların, ergenlerin ve gençlerin gerçek dünya ile kurgusal dünya arasında gidip gelmelerini olanaklı kılan yaratıcı drama çalışmalarının genel amacı, her alanda kendine yetebilen, kendini tanıyan, çevresiyle iletişim kurabilen ve bu geliştirilebilen, ifade gücü ve biçimleri artmış bireyler yetiştirmektir." Yaratıcı drama çalışmalarının temel amaçları arasında sayılan kendini tanıma, hem ergenlik sürecine özgü en temel kazanımlardan biri olması ile hem de eğitsel/mesleki hedef belirleme sürecinin temel yapı taşlarından bir olması dolayısıyla bu çalışmada önemli görülmektedir. Grup rehberliği ise okul rehberlik servislerinde ortak sorun alanlarına sahip öğrenciler ile yürütülen grup çalışmalarıdır. Kuzgun (2002) grup rehberliğinin amaçlarını şöyle belirtmektedir:

- Kimliğini bulmada bireye yardımcı olmak,

- Bireyin kendini daha olumlu bir biçimde değerlendirmesine, kendine güven geliştirmesine yardımcı olmak,

- Kişinin duygu, düşünce ve davranışları arasındaki tutarlılığın artmasına yardımcı olmak,

- Kişiye değer yargılarını gözden geçirmesi ve geçerliliklerini sınaması için gerekli ortamı sağlamak,

- Bireye başka insanları dinlemeyi, anlamayı ve başkaları ile iletişim kurabilmenin yollarını öğretmek,

- Başkaları ile özellikle anne babası, öğretmenleri, otorite figürleri ve akranları ile ilişkilerini irdelemesi için bireye gerekli firsatları sağlamak.

$\mathrm{Bu}$ amaçlar düşünüldüğünde grup rehberliği yönteminin bu çalışmada ele alınan ve ulaşılmak istenen hedefler ile örtüştüğü belirtilebilir.

Grup rehberliği ve yaratıcı drama yöntemleri ile eğitsel ve mesleki hedef belirlemeye ilişkin verilen eğitimin, öğrencilerin meslek kararı verme, eğitsel hedef belirleme karar süreçlerinde bir değişiklik oluşturup oluşturmayacağı araştırmanın problemini oluşturmaktadır.

\section{Araştırmanın Amacı}

Çalışmanın genel amacı, ortaokul yedinci sınıfa devam eden öğrencilerin meslek kararı verme ve eğitsel/mesleki hedef belirleme karar süreçlerinde yaratıcı drama ve grup rehberliği yöntemlerinin etkililiğinin değerlendirilmesidir. Bu amaç doğrultusunda, aşağıdaki denenceler test edilmiştir:

- Grup rehberliği grubuna katılan öğrencilerin meslek kararı verme yetkinlikleri artacaktır.

- Yaratıcı drama oturumuna katılan öğrencilerin meslek kararı verme yetkinlikleri artacaktır. 
- Grup rehberliğgi grubuna katılan öğrencilerin öz kavramı puanları artacaktır.

- Yaratıcı drama oturumuna katılan öğrencilerin öz kavramı puanları artacaktır.

- Yaratıcı drama oturumuna katılan öğrencilerin meslek seçim sürecinde etkili olan faktörlere ilişkin yaptıkları tanımlar belirginleşecektir.

- Yaratıcı drama oturumuna katılan öğrencilerin kısa, orta ve uzun süreli hedefleri belirginleşecektir.

- Yaratıcı drama oturumuna katılan öğrencilerin üst eğitim kurumuna ilişkin hedefleri belirginleşecektir.

- Yaratıcı drama oturumuna katılan öğrencilerin mesleki hedefleri belirginleşecektir.

- Grup rehberliği grubuna katılan öğrencilerin meslek seçim sürecinde etkili olan faktörlere ilişkin yaptıkları tanımlar belirginleşecektir.

- Grup rehberliği grubuna katılan öğrencilerin kısa, orta ve uzun süreli hedefleri belirginleşecektir.

- Grup rehberliği grubuna katılan öğrencilerin üst eğitim kurumuna ilişkin hedefleri belirginleşecektir.

- Grup rehberliği grubuna katılan öğrencilerin mesleki hedefleri belirginleşecektir.

\section{Yöntem}

Araştırma grubunu Ankara ili Mamak ilçesi Şehitler İlköğretim Okulu'nda 2009-2010 eğitim öğretim yılında yedinci sınıfta eğitime devam eden öğrencilerden tesadüfi olarak seçilen 45 öğrenci oluşturmaktadır. Yaratıcı drama programı $10 \mathrm{kız} 5$ erkek olmak üzere toplam 15 öğrenciye ve grup rehberliği programı 7 kız 8 erkek olmak üzere toplam 15 öğrenciye uygulanmıştır. Kontrol grubunda ise 7 kız 8 erkek olmak üzere toplam 15 öğrenci bulunmaktadır. Yaratıcı drama, grup rehberliği ve kontrol gruplarına öğrenciler tesadüfi olarak seçilmiştir. Uygulama öncesinde tüm öğrencilere MKVYÖ, KHDÖ ve araştırmacı tarafından geliştirilen anket uygulanmış, daha sonra yaratıcı drama ve grup rehberliği oturumları yapılmış ve oturumlar sonrası aynı ölçme araçları ile son test uygulaması gerçekleştirilmiştir.

MKVYÖ ve KHDÖ’den elde edilen verilerin analizinde Wilcoxon işaretli sıralar testi kullanılmıştır. Söz konusu test, tek örneklem t-testinin nonparametrik karşılığıdır. Nonparametrik testler normallik varsayımının karşılanmadığı durumlarda kullanılmaktadır. İşaretli sıralar testi, pozitif ve negatif değerlerin arasındaki farkların hesaplanarak karar verilmesine dayalı basit bir yöntemdir (Elliott, Woodward, 2007) ve veriler eşit aralık ölçeğinde olduğunda kullanılabilmektedir. Tüm bu nedenlerle çalışmada Wilcoxon işaretli sıralar testi kullanılmıştır. Araştırmacı tarafından geliştirilen anket ise nitel analiz yöntemlerinden içerik analizi ile incelenmiştir. Nitel araştırma, insanların olaylara ne tür anlamlar yükledikleri, yani olayları nasıl niteledikleri sorusuna cevap aramaktadır (Dey, 1993). İçerik analizinde ise temel amaç, elde edilmiş olan bulguların okuyucuya özetlenmiş ve yorumlanmış bir biçimde sunulmasıdır (Yıldırım ve Şimşek, 2003).

Araştırmanın bir sınırlılığı olarak ise çalışmada kullanılan yöntemlerden yaratıcı drama ve grup rehberliğinin etkili bir şekilde uygulanması için gruplara katılan öğrenci sayıları 15 kişi sınırında tutulması belirtilebilir.

\section{Araştırmanın Modeli}

$\mathrm{Bu}$ çalışma, iki farklı eğitim programının öğrencilerin eğitsel/mesleki hedef belirleme davranışları üzerindeki etkisini saptamayı amaçlayan deneysel bir çalışmadır. Araştırmada ön test son test kontrol gruplu desen kullanılmıştır. 


\section{Veri Toplama Araçları}

Araştırmada yaratıcı drama ve grup rehberliği programlarının etkililiğinin değerlendirilmesi amacıyla "Piers- Harris'in Çocuklarda Öz Kavramı Ölçeği”, "Meslek Kararı Verme Yetkinlik Ölçeği” ve araştırmacı tarafından hazırlanan açık uçlu sorulardan oluşan anket formu kullanılmıştır.

Piers- Harris'in Çocuklarda Öz Kavramı Ölçeği (KHDÖ): Ölçek, Piers ve Haris (1964) tarafından öğrencilerin kendilerine ilişkin duygu, düşünce ve tutumlarını belirlemek amacıyla geliştirilmiştir (Öner, 2005). Ölçeğin standardizasyonu 3.-12. sınıf öğrencileri ile yapılmıştır. İç tutarlılık katsayısı .78- .93 arasında değişmektedir. Ölçek 6 faktör ve 80 maddeden oluşmaktadır. Ölçeğin Türkçeye uyarlanma sürecinde faktörlerin sıralanması farklılaşsa da aynı faktörler uyarlama sürecinin sonucunda Türkçe ölçekte de bulunmuştur.

Meslek Kararı Verme Yetkinlik Ölçeği (MKVYÖ): Bozgeyikli (2004) tarafından öğrencilerin meslek kararı verme yetkinlik düzeylerini belirlemek amacıyla geliştirilmiştir. Ölçek toplam 27 madde ve üç faktörden oluşmaktadır. Faktörler Bireysel ve Mesleki Özellikleri Doğru Olarak Değerlendirme”, "Mesleki Bilgi toplama" ve "Gerçekçi Plan Yapma" olarak adlandırılmıştır.

Anket Formu: Araştırmacı tarafından öğrencilerden meslek seçiminde önemli olduğu bilinen kavramlara ilişkin bilgi almak amacıyla hazırlanmıştır. Bu amaçla altı açık uçlu soru sorulmuştur. Sorular; "İlgi nedir?”, "Yetenek nedir?”, "Kişilik özelliği nedir?”, "Kendiniz için kısa, orta ve uzun vadedeki hedefleriniz neler?” "Hangi üst eğitim kurumuna gitmek istiyorsunuz?” ve "Hangi meslekleri seçmek istiyorsunuz? olarak belirlenmiştir.

\section{Verilerin Toplanması}

Eğitim programları uygulanmadan önce "KHDÖ”, "MKVYÖ" ve anket formu ile ön test çalışması yapılmıştır. Daha sonra eğitim programı uygulanmış ve programın hemen ardından son test çalışması yapılmıştır.

\section{Verilerin Analizi}

Verilerin analizi aşamasında SPSS 13 paket programı kullanılmıştır. "MKVYÖ” ile "KHDÖ” ön test son test sonuçlarının değerlendirilmesinde nonparametrik analiz yöntemlerinden Wilcoxan işaretli sıralar testi kullanılmıştır.

\section{Uygulama}

Araştırmada yaratıcı drama ve grup rehberliği yöntemlerinin eğitsel/mesleki hedef belirleme sürecindeki etkililiğinin değerlendirilmesi amaçlanmıştır. Yaratıcı drama sözlü anlatım yöntemlerinden farklı olarak, katılımcıyı sürekli aktif tutması ve bu nedenle de tam öğrenmenin gerçekleştiğinin vurgulanması nedeniyle tercih edilmiştir. Grup rehberliği ise hali hazırda okul rehberlik birimlerinde kullanılan ve özellikle eğitsel/mesleki rehberlik çalışmalarında çoğunlukla tercih edilen bir yöntem olması nedeniyle kullanılmıştır. Uygulamalarda hem yaratıcı drama hem de grup rehberliği oturumlarının sayıları, oturum süreleri ve kazanımları aynı belirlenmiş ve bunlardan kaynaklanabilecek bir farklılaşma en aza indirilmeye çalışılmıştır. Yaratıcı drama ve grup rehberliği oturumlarının başlıkları ve kazanımları aşağıda belirtilmektedir:

\section{Oturum: Tanışma}

- Gruptaki kişilerin isimlerini söyler.

- Gruba katılır.

\section{Oturum: İlgiler}

- İlginin tanımını yapar. 
- Herkesin ilgilerinin farklı olabileceğini fark eder.

- İlgilerin seçimleri etkilediğini bilir.

\section{Oturum: Yetenekler}

- Yetenek alanlarının isimlerini söyler.

- Yetenek alanlarının hangi yetenekleri kapsadığını bilir.

- Kendi yeteneklerini fark eder.

- Yeteneklere uygun alan seçiminin önemini fark eder.

\section{Oturum: Kişilik özellikleri}

- Kişilik özelliklerine örnek verir.

- Kendi kişilik özelliklerini fark eder.

\section{Oturum: Hedef belirleme}

- Hedef belirlemenin önemini fark eder.

- Hedef belirlemede çevrenin etkilerini bilir.

- Günlük yaşamda karşılaşıllabilecek engelleri söyler.

\section{Oturum: Üst eğitim kurumları}

- Üst eğitim kurumlarının isimlerini sayar.

- Üst eğitim kurumları hakkında bilgi edinir.

\section{Oturum: Meslekler}

- Meslek seçmede etkili olan faktörleri fark eder.

- Meslekler hakkında bilgi sahibi olur.

\section{Bulgular}

$\mathrm{Bu}$ bölümde MKVYÖ ve KHDÖ'den elde edilen veriler ile uygulanan anketin sonuçları değerlendirilmiştir. Araştırmanın nicel verilerinin analizinde Wilcoxon işaretli sıralar testi, nitel verilerin analizinde ise içerik analizi kullanılmıştır.

\section{MKVYÖ’ye İlişkin Bulgular}

MKVYÖ puanlarının Wilcoxon işaretli sıralar testi sonucunda, yaratıcı drama grubuna katılan öğrencilerin ön test ( $\bar{X}=114,33$ ) ve son test puanları ( $\bar{X}=118,67$ ) arasında $\alpha=0,05$ düzeyinde anlamlı fark bulunmuştur. Aynı şekilde grup rehberliği oturumlarına katılan öğrencilerin ön test ( $\bar{X}=116,13)$ ve son test puanları $(\bar{X}=121,07)$ arasında $\alpha=0,05$ düzeyinde anlamlı fark bulunmuştur. Buna göre öğrencilerin yaratıcı drama ve grup rehberliği oturumları sonrası meslek kararı verme yetkinlik düzeyleri artmıştır. Kontrol grubunda olan öğrencilerin ise ön test ( $\bar{X}=117,93$ ) ve son test puanları ( $\bar{X}=119,07$ ) arasında $\alpha=0,05$ düzeyinde anlamlı fark bulunmamıştır.

\section{KHDÖ’ye İliş̧kin Bulgular}

KHDÖ'ne puanlarının Wilcoxon işaretli sıralar testi sonucunda, yaratıcı drama grubuna katılan öğrencilerin ön test ( $\bar{X}=64,87)$ ve son test $(\bar{X}=66,00)$ puanları; grup rehberliği grubuna katılan öğrencilerin ön test ( $\bar{X}=61,67)$ ve son test ( $\bar{X}=60,93)$ puanlar1; kontrol grubundaki öğrencilerin ön test $(\bar{X}=61,93)$ ve 
son test ( $\bar{X}=65,13$ ) puanları arasında $\alpha=0,05$ düzeyinde anlamlı fark bulunmamıştır. Buna göre yaratıcı drama ve/veya grup rehberliği oturumlarına katılan öğrencilerin öz benlik algılarında uygulanan program sonrasında anlamlı bir fark yoktur.

\section{Anket Uygulamasına İlişkin İçerik Analizi Sonuçları}

\section{Tablo 1. "İlgi nedir?” Sorusu İçerik Analizi Sonuçları}

\begin{tabular}{|c|c|c|c|c|c|}
\hline \multicolumn{2}{|c|}{ Yaratıcı Drama } & \multicolumn{2}{|c|}{ Grupla Danışma } & \multicolumn{2}{|c|}{ Kontrol Grubu } \\
\hline Ön test & Son test & Ön test & Son test & Ön test & Son test \\
\hline Merak & Merak & Merak & Merak & Merak & Merak \\
\hline İstek & İstek & İstek & İstek & İstek & İstek \\
\hline $\begin{array}{l}\text { Hosslanma / } \\
\text { Sevgi }\end{array}$ & Hoşlanma / Sevgi & Yetenek & -------- & $\begin{array}{c}\text { Hoşlanma / } \\
\text { Sevgi }\end{array}$ & Hoşlanma / Sevgi \\
\hline \multirow[t]{2}{*}{ Diğer } & Diğer & $\begin{array}{c}\text { Hoşlanma / } \\
\text { Sevgi }\end{array}$ & $\begin{array}{c}\text { Hoşlanma / } \\
\text { Sevgi }\end{array}$ & Diğer & Diğer \\
\hline & & Diğger & Diğger & & \\
\hline
\end{tabular}

Yaratıcı drama grubuna katılan öğrencilerin ön anket ve son anket cevapları "merak", “istek”, "hoşlanma/sevgi” ve "diğer" tema başlıklarında toplanmaktadır. Öğrencilerin ilgiyi daha çok "merak” kavramı ile tanımladıkları görülmektedir. Ön anket ve son anket cevapları birbirleri ile paraleldir.

Grup rehberliği grubuna katılan öğrencilerin ön anket cevapları "merak”, "istek”, “yetenek”, "hoşlanma/ sevgi" ve "diğer" tema başlıklarında toplanmaktadır. Ön anket sonuçlarında bulunan "yetenek" teması son anket sonuçlarında oluşmamıştır. Öğrencilerin ilgiyi daha çok "merak” kavramı ile tanımladıkları görülmektedir.

Kontrol grubuna katılan öğrencilerin ön anket ve son anket cevapları "merak", "istek", "hoşlanma/sevgi” ve "diğer" tema başlıklarında toplanmaktadır. Öğrencilerin ilgiyi daha çok "merak" kavramı ile tanımladıkları görülmektedir. Ön anket ve son anket cevapları birbirleri ile paraleldir.

Tablo 2. Yetenek nedir?" Sorusu İçerik Analizi Sonuçları

\begin{tabular}{|c|c|c|c|c|c|}
\hline \multicolumn{2}{|c|}{ Yaratıcı Drama } & \multicolumn{2}{|c|}{ Grupla Danışma } & \multicolumn{2}{|c|}{ Kontrol Grubu } \\
\hline Ön test & Son test & Ön test & Son test & Ön test & Son test \\
\hline Yapabilmek & Yapabilmek & Yapabilmek & Yapabilmek & Yapabilmek & Yapabilmek \\
\hline Başarı & -------------- & Başarı & ------------ & $\begin{array}{l}\text { İyi olmak/ } \\
\text { beceri }\end{array}$ & $\begin{array}{l}\text { İyi olmak / } \\
\text { beceri }\end{array}$ \\
\hline $\begin{array}{l}\text { İyi olmak / } \\
\text { beceri }\end{array}$ & $\begin{array}{l}\text { İyi olmak/ } \\
\text { beceri }\end{array}$ & $\begin{array}{l}\text { İyi olmak / } \\
\text { beceri }\end{array}$ & $\begin{array}{l}\text { İyi olmak / } \\
\text { beceri }\end{array}$ & Diğer & Diğer \\
\hline Diğer & Diğer & Diğer & Diğger & & \\
\hline Yapabilmek & Yapabilmek & Yapabilmek & Yapabilmek & Yapabilmek & Yapabilmek \\
\hline
\end{tabular}


Yaratıcı drama grubuna katılan öğrencilerin verdiği cevaplar "yapabilmek”, "başarı", "iyi olmak/beceri” ve "diğer" başlıklı temalarda toplanmaktadır. Son anket sonuçlarında "başarı" teması dışındaki diğer temalar oluşmuştur. Öğrencilerin cevaplarının en çok “yapabilmek” teması altında toplandığı görülmektedir.

Grup rehberliği grubuna katılan öğrencilerin verdiği cevaplar "yapabilmek”, "başarı”, "iyi olmak/beceri” ve "diğer" başlıklı temalarda toplanmaktadır. Son anket sonuçlarında "başarı" teması dışındaki diğer temalar oluşmuştur. Öğrencilerin cevaplarının en çok “yapabilmek” teması altında toplandığı görülmektedir.

Kontrol grubuna katılan öğrencilerin verdiği ön ve son anket cevapları "yapabilmek”, "iyi olmak/beceri” ve "diğer" başlıklı temalarda toplanmaktadır. Öğrencilerin cevaplarının en çok "iyi olmak/beceri”" teması altında toplandığı görülmektedir.

Tablo 3. Kişilik özelliği nedir? Sorusu İçerik Analizi Anket Sonuçları

\begin{tabular}{cccccc}
\hline \multicolumn{2}{c}{ Yaratıcı Drama } & \multicolumn{2}{c}{ Grupla Danı̧̧ma } & \multicolumn{2}{c}{ Kontrol Grubu } \\
\hline Ön test & Son test & Ön test & Son test & Ön test & Son test \\
\hline $\begin{array}{c}\text { Kişiye Özgü } \\
\text { Özellikler }\end{array}$ & $\begin{array}{c}\text { Kişiye Özgü } \\
\text { Özellikler }\end{array}$ & $\begin{array}{c}\text { Kişiye Özgü } \\
\text { Özellikler }\end{array}$ & $\begin{array}{c}\text { Kişiye Özgü } \\
\text { Özellikler }\end{array}$ & $\begin{array}{c}\text { Kişiye Özgü } \\
\text { Özellikler }\end{array}$ & $\begin{array}{c}\text { Kişiye Özgü } \\
\text { Özellikler }\end{array}$ \\
\hline Davranış & Davranış & Diğer & Diğer & Diğer & Diğer \\
\hline İçsel Özellikler & $------------~$ & & Davranış & Davranı̧̧ \\
\hline Diğer & Diğer & & & \\
\hline
\end{tabular}

Yaratıcı drama grubuna katılan öğrencilerin ön anket cevapları "içsel özellikler”, "davranış” ve "diğer” başlıklı temalarda toplanmaktadır. Son ankette "içsel özellikler” teması oluşmamış ancak "kişiye özgü özellikler” teması oluşmuştur. Bu tema frekansı en yüksek tema olarak belirlenmiştir.

Grup rehberliği grubuna katılan öğrencilerin cevaplanı "kişiye özgü özellikler" ve "diğer" başlıklı temalarda toplanmaktadır. Son anket cevaplarında "davranış" teması bulunmaktadır. Ancak frekansı en yüksek tema ön anket ve son anket sonuçlarında "kişiye özgü özellikler” olarak belirlenmiştir.

Kontrol grubuna katılan öğrencilerin cevapları "kişiye özgü özellikler" ve "diğer" başlıklı temalarda toplanmaktadır. Öğrencilerin cevaplarının en çok "kişiye özgü özellikler" başlıklı temada toplandığ 1 görülmektedir. Son anket sonuçlarında “davranış" teması oluşmuştur. Ancak frekansı en yüksek tema “diğer"dir.

Tablo 4. "Hangi üst eğitim kurumuna gitmek istiyorsunuz?” ve "Hangi meslekleri seçmek istiyorsunuz?" Sorularının İçerik Analizi Sonuçları

\begin{tabular}{ccccccc}
\hline Gruplar & $\begin{array}{c}\text { Üst eğitim kurumu ve meslek } \\
\text { paralel }\end{array}$ & $\begin{array}{c}\text { Üst eğitim kurumu ve } \\
\text { meslek paralel değil }\end{array}$ & $\begin{array}{c}\text { Üst eğitim kurumu yanlış } \\
\text { ifade edilmiş }\end{array}$ \\
\hline & Ön test & Son test & Ön test & Son test & Ön test & Son test \\
\hline Yaratıcı drama & 15 & 22 & 2 & 9 & 1 & 1 \\
\hline Grup rehberliği & 10 & 18 & 10 & 9 & & 2 \\
\hline Kontrol & 11 & 10 & 8 & 9 & 1 & 2 \\
\hline
\end{tabular}


Yaratıcı drama grubuna katılan öğrencilerin ön anket cevaplarına göre 15 üst eğitim kurumu ile meslek paralellik göstermektedir, bir üst eğitim kurumu yanlış ifade edilmiştir, seçilen iki üst eğitim kurumu ile meslek arasında ise paralellik bulunmamaktadır. Son anket cevaplarında ise öğrencilerin belirttikleri 22 üst eğitim kurumu ile meslek arasında paralellik bulunduğu, bir üst eğitim kurumunun yanlış ifade edildiği, seçilen dokuz üst eğitim kurumu ile meslek arasında ise paralellik bulunmadığı görülmektedir.

Grup rehberliği grubuna katılan öğrencilerin ön anket cevaplarına göre belirttikleri on üst eğitim kurumu ile meslek arasında paralellik bulunurken seçilen on üst eğitim kurumu ile meslek arasında paralellik bulunmamaktadır. Son anket cevaplarına göre ise 18 üst eğitim kurumu ile meslek arasında paralellik bulunduğu, iki üst eğitim kurumunun yanlış ifade edildiği, seçilen dokuz üst eğitim kurumu ile meslek arasında ise paralellik bulunmadığı görülmektedir.

Kontrol grubuna katılan öğrencilerin cevaplarında belirttikleri 11 üst eğitim kurumu ile meslek arasında paralellik bulunduğu, bir üst eğitim kurumunun yanlış ifade edildiği, seçilen sekiz üst eğitim kurumu ile meslek arasında ise paralellik bulunmadığı görülmektedir. Son anket cevaplarına göre ise öğrencilerin belirttikleri 10 üst eğitim kurumu ile meslek arasında paralellik bulunduğu, iki üst eğitim kurumunun yanlış ifade edildiği, seçilen dokuz üst eğitim kurumu ile meslek arasında ise paralellik bulunmadığı görülmektedir.

\section{Sonuç ve Öneriler}

Araştırmalar öğrencilerin meslek seçim süreçlerine olumlu katkı sağlaması bakımından eğitsel/mesleki rehberlik uygulamalarının etkililiğini kanıtlamaktadır (Ayas, Deniz ve Kağan, 2010; Bacanl1, 1995, 2005; Bal, 1998; Bozgeyikli,2005; Evren, 1999; İşgör ve Sezer, 2008; Kırdök, 2006; Makro ve Savickas, 1998; Symes, 1998; Uskaner, 1999). Bu çalışmada da öğrencilerin mesleki karar verme yetkinlik düzeylerini artırmada yaratıcı drama ve grup rehberliği oturumlarının etkili olduğu görülmüştür. Bu sonuç Bozgeyikli (2008) tarafından yapılan mesleki grup rehberliğinin ilköğretim 8. sınıf öğrencilerinin meslek kararı verme yetkinlik düzeylerine etkisinin araştırıldığı çalışmanın sonuçları ile de tutarlılık göstermektedir. Söz konusu çalışmada 8. sınıf öğrencilerinin uygulanan deneysel işlem sonucunda meslek kararı verme yetkinlik düzeylerinin arttığı belirtilmiştir.

Araştırmanın bir başka sonucu olarak öğrencilerin öz kavramlarını değiştirmede yaratıcı drama ve grup rehberliği uygulamalarının etkili olmadığı görülmüştür. Öz kavramı bireyin ergenlik döneminin en temel sorusu “Ben kimim?”e verilen cevap olarak karşımıza çıkmaktadır. Fiziksel, sosyal ve ruhsal alanda değişimler yaşayan birey, yaşamın tüm alanlarında kendini tanımlayarak öz kavramını oluşturur. Çalışmada eğitsel/mesleki karar sürecine ilişkin yetkinliği artırmaya yönelik program uygulamaları yapılmıştır. Bu amacın, uygulanan programın öğrencilerin fiziksel, ruhsal ve sosyal alanda yaşadıkları tüm değişimlere ve sorunlara cevap verememe ve öz kavramlarını değiştirmede yeterli olmadığı düşünülmektedir. Yalnızca öz kavramını yükseltmek amacıyla yapılmış sosyal beceri eğitimine yönelik çalışmada (Cerrahoğlu, 2002) bu amacın gerçekleştiği bulgulanmıştır.

Çalışmanın nitel verilerine bakıldığında, program uygulamaları süresince işlenen ilgi, yetenek ve kişilik özellikleri kavramlarına ilişkin tanımların son anket cevaplarının ön anket cevaplarına göre sözlük tanımlarına daha yakın olduğu gözlenmiştir. Ancak kısa, orta ve uzun vadeli hedef belirleme ile üst eğitim kurumu ile meslek arasında paralelliğe bakıldığında ön anket ile son anket cevapları birbiri ile paralellik göstermektedir. Bu sonuç hedef belirleme konusunda öğrencilerin daha fazla desteklenmesi gerektiğini göstermektedir. Öğrencilerin hedef üst eğitim kurumlarını ve meslekleri tanımaya yönelik daha pek çok yapılandırılmış çalışmaya ihtiyaç duydukları görülmektedir. Bu nedenle bundan sonra yapılacak çalışmalarda bu konuların özel olarak çalışılması gerektiği belirtilebilir. 
Araştırmada genel amaç çerçevesinde değerlendirilen öğrencilerin eğitsel/mesleki hedef belirlemede kendilerini yetkin görme düzeylerinin arttığı belirtilebilir. Bu nedenle bu çalışmada uygulanmış hem yaratıcı drama hem de grup rehberliği programlarının okullarda öğrencilerin hedef belirleme yetkinliklerini arttırmada kullanılabileceği düşünülmektedir.

\section{Kaynaklar}

Adıgüzel, H. Ö. (2001). Niçin Yaratıcı Drama?. Öğretmen Dünyası Dergisi. ( 257) , 13-16.

Akbalık, G. (1991). Ortaokul III. Sınıf Öğrencilerinin Mesleki Olgunluk Düzeyleri. Ankara Üniversitesi Sosyal Bilimler Enstitüsü Eğitimde Psikolojik Hizmetler Anabilim Dalı. Yayımlanmamış Yüksek Lisans Tezi.

Ayas, T., Deniz, M. ve Kağan, M. (2010). Ginzberg ve Arkadaşlarının Gelişim Kuramına Dayalı Örnek Bir Mesleki Grup Rehberliği Çalışması. Uluslararası İnsan Bilimleri Dergisi, 7 (2), 1096-1117.

Bacanlı, F. (1995). Mesleki Grup Rehberliğinin Lise Öğrencilerinin Mesleki Olgunluk Düzeylerine Etkisi. Yayımlanmamış Doktora Tezi, Gazi Üniversitesi Sosyal Bilimler Enstitüsü, Ankara.

Bacanlı, F. (2005). Lise Öğrencileri İçin Mesleki Grup Rehberliği Programı ve Uygulama Kılavuzu. Ankara: Nobel Yayın Dağıtım.

Bal, P. N. (1998). "Ergenlik Döneminde Mesleki Karar Verme Olgunluğunun incelenmesi ve "Mesleki Karar Verme Eğitim Programı”nın Etkisinin Araştırılması", Yayımlanmamış Doktora Tezi, Marmara Üniversitesi Eğitim Bilimleri Enstitüsü, İstanbul.

Bozgeyikli, H., (2004) Meslek Kararı Verme Yetkinlik Ölçeğinin Geliştirilmesi. Selçuk Üniversitesi Sosyal Bilimler Enstitüsü Dergisi, 11, 221-234

Bozgeyikli, H. (2005). Mesleki Grup Rehberliğinin İlköğretim 8. Sınıf Öğrencilerinin Meslek Kararı Vermede Kendilerini Yetkin Görme Düzeylerine Etkisi. Selçuk Üniversitesi Sosyal Bilimler Enstitüsü Eğitim Bilimleri Ana Bilim Dalı. Yayımlanmamış Doktora Tezi.

Bozgeyikli, H. (2008). Mesleki Grup Rehberliğinin ilköğretim 8. Sınıf öğrencilerinin Meslek Kararı Verme Yetkinlik Düzeylerine Etkisi. Kazım Karabekir Eğitim Fakültesi Dergisi.

Cerrahoğlu, S. (2002). Sosyal Beceri Eğitiminin İlköğretim Öğrencilerinin Öz kavramı Düzeylerine Etkisi, Yayımlanmış Yüksek Lisans Tezi, Ankara.

Çoban, A. E. (2005). Lise Son Sınıf Öğrencilerinin Mesleki Olgunluk Düzeylerinin Yordayıcı Bazı Değişkenlere Göre İncelenmesi. İnönü Üniversitesi eğitim Fakültesi Dergisi. 6(109), 39-54.

Dey, I. (1993). Creating categories. Qualitative Data Analysis, London: Routledge.

Elliott, A.C.,Woodward, W.A. (2007). Statıstıcal Analysıs Quick Reference Guidebook With Spss Examples, Nonparametric Analysis Procedures. California, Sage Publications

Evren, M. (1999), "Mesleki Grup Rehberliğinin İlköğretim Okulu Sekizinci Sınıf Öğrencilerinin Mesleki Olgunluk, Mesleki Benlik Algıları ve Mesleki Tercihlerine Etkisi”, Yayınlanmamş Yüksek Lisans Tezi, Hacettepe Üniversitesi Sosyal Bilimler Enstitüsü, Ankara.

Ginzberg, E., Ginsburg, S. W., Axelrad, S., Herma, J. L. (1951). Occupational choice. New York.

Herr, E.L. \& Crammer, S.H. (1996). Career Guidance And Counseling Through The Lifespan (5th Ed), New York: HarperCollins Publishers.

Herr, E. L. (2001). Career Development And İts Practice: A Historical Perspective. The Career Development Quarterly, 49 (3), 196-211.

Isaacson, L. E., \& Brown, D. (1997). Career İnformation, Career Counseling and Career Development. Boston: Allyn and Bacon.

İşgör, İ. Y. ve Sezer, F. (2008). Mesleki Olgunluk Anlayışı Kazandırmaya Yönelik Sınıf İçi Rehberlik Etkinlikleri Program Denemesi. Frrat Üniversitesi Sosyal Bilimler Dergisi, 18-2,239-252.

Kırdök, O. (2006), "Bilgiyi İşleme Kuramına Dayalı Mesleki Grup Rehberliği Programının Geliştirilmesi ve Uygulamasına Yönelik Bir Çalışma”, 1. Ulusal Psikolojik Danışma ve Rehberlik Uygulamaları Kongresi, Mersin. 
Köküsoy, K. (2008) Endüstri Meslek Liselerinde Bir Meslek Alanına Yönelmiş Olan Öğrencilerin Mesleki Olgunluk Ve Algıladıkları Aile Desteği Düzeylerinin İncelenmesi. Yüksek Lisans Tezi, İstanbul: Yeditepe Üniversitesi Sosyal Bilimler Enstitüsü.

Kuzgun, Y. (2002). Rehberlik ve Psikolojik Danışma. (8. Baskı). Ankara: ÖSYM Yayınları.

Kuzgun, Y. (2009). Meslek Gelişimi ve Danışmanlığı. (3. Baskı) Ankara Nobel Yayın.

Makro, K. W. ve Savickas, M. L.(1998), “Effectiveness of a Career Time Perspective Intervention”, Journal of Vocational Behavior, 52: 106-119.

Oğuz, Ö. (2008). Lise Öğrencilerinin Mesleki Olgunluk Düzeylerinin Bazı Değişkenlere Göre İncelenmesi (Özel Arı Lisesi Örneği). Yayımlanmamış Yüksek Lisans Tezi, Ankara Üniversitesi Eğitim Bilimleri Enstitüsü, Ankara.

Öner, N. (2005). Piers-Harris Çocuklarda Öz Kavramı Ölçeği El Kitabı. Ankara: Türk Psikologlar Derneği.

Özgan, A. (2006). Meslek Lisesi Öğrencilerinin Mesleki Karar Verme Olgunluğu İle Bazı Kişilik Özelliklerinin İncelenmesi. Marmara Üniversitesi Fen Bilimleri Enstitüsü. Yayımlanmamış Yüksek Lisans Tezi.

Özgüven, İ. E. (2000). Çağdaş Eğitimde Psikolojik Danışma ve Rehberlik, Sistem Ofset, Ankara.

Symes, B.A. (1998), “Group Counselling for Vocational Decidedness", Guidance and Counseling, 13 (2).

Tokar, D.M., Fisher, A.R., Subich, L.M. (1998). "Personality and Vocational Behavior: A Selective Review of the Literature", Journal of Vocational Behavior, 53, 115-153.

Uskaner, A. (1999). Mesleki Grup Rehberliğinin Lise Birinci Sınıf Öğrencilerinin Mesleki Olgunluk Düzeylerine Etkisi. Yayınlanmamış yüksek lisans tezi, Çukurova Üniversitesi Sosyal Bilimler Enstitüsü, Adana.

Whiston, S. C., \& Keller, B. K. (2004). The Influences of the Family of Origin on Career Development A Review and Analysis. The Counseling Psychologist, 32(4), 493-568.

Yıldırım, A., Şimşek, H. (2003). Sosyal Bilimlerde Nitel Araştırma Yöntemleri. Ankara: Seçkin Yayınları .

Zeren, Ş. G. (1999). Yabancı Dil Ağırlıklı Lise, Özel Lise ve Anadolu Lisesi Son Sınıf Öğrencilerinin Mesleki Olgunluk Düzeyleri. Yayımlanmamış yüksek lisans tezi, Hacettepe Üniversitesi, Ankara. 


\title{
The Implementation of Creative Drama and Group Counseling Programs in the Process of Educational/Vocational Goal Setting
}

\author{
Derya Atalan Ergin ${ }^{3}$
}

Nejat Akfirat ${ }^{4}$

\begin{abstract}
Introduction
The fundamental aim of education is to raise individuals who know and actualize themselves. Acknowledging the fact that this fundamental aim consists of various sub-aims, it can be said that one of the most important sub-aims is for the individual to attain vocational maturity and to be able to set a vocational goal for themselves. Educational and career development is considered as a process in the theories in the literature. This process mostly starts in the pre-school period and continues through adulthood, when the individual is anticipated to have had a profession, and according to some theories it continues even through lifetime. In theories which emphasize that individuals progress in stages, the individual reaches vocational maturity through achieving the desired development tasks in each stage. Bacanlı (1995) defines the process of vocational maturity as having a number of typical and necessary problem-solving experiences (career development tasks) encountered in each stage of career development and acquiring these fundamental skills in order to be ready for the development tasks in the subsequent stage. These experiences and skills make it possible for the individual to choose a career that matches well with his or her interests and abilities. Studies have shown that the individual's choice of career is influenced by his or her personality traits as well as other factors such as the individual's values, career interests, and expected career satisfaction (Tokar, Fisher ve Subich,1998).
\end{abstract}

Career development process, which takes place as a result of the interplay among various individual and environmental factors according to the development properties and cognitive state of the child and the adolescent, is suggested to be of five stages (Özgüven, 2000: 151-152):

- Awakening and Awareness: It is the stage from pre-school period through the end of primary school. At the beginning of the stage, the child becomes aware of the occupations in his environment and notices that people have different jobs. Through the end of the stage, the child starts to recognize that there are similarities and differences between himself and other people in terms of interests, talents, goals, and motivation.

- Discovering and Searching Vocations: In this stage, which begins in the secondary school and continues through lifetime for many people, vocations and people are closely examined and the congruence between one's personality and choice of career is evaluated.

- Decision-making: In this stage, which takes place during high school years, the individual starts to match his own personality traits and specific features of vocations and to gradually identify appropriate choice of career for himself or herself.

- Preparation: In this stage of preparation for vocation, the individual develops his or her knowledge and skills about the vocation he or she is going to choose. He or she starts to look for job options within the career field he or she is interested in and might prolong the preparation process.

3 Teacher, Ministry Education, deryaatalan@gmail.com

4 Teacher, Ministry Education, nejatakfirat@gmail.com 
- Getting into a Job: In this stage, the individual starts to put the knowledge and skills he or she has learned into practice. Getting into a job is the stage in which career development continues and the knowledge and skills continue to grow.

Theories of career choice can be said to center around two approaches. The first approach takes choice of career as a process, whereas the second approach includes theories that focus on the relations between personality traits and vocations.

Theoreticians who posit that choice of career is a process are Ginzberg, Ginsburg, Axelrad and Herma (1951). The theory suggests that the individual makes his or her career choice not based on an instant decision, but through behavior patterns that are formed and developed over lifetime and are to a great extent irrevocable (Kuzgun, 2002). The stages are named as fantasy stage, tentative choice stage, and realistic choice stage. In another theory, Super suggests that career development is lifelong. The stages, in which the development of self-concept and career choice takes place, are named as growth, exploration, establishment, maintenance, and decline.

"Trait and Factor Theory" falls into the second approach, which handles career development in relation to personality traits. In the trait and factor theory, which is at the center of this approach and which made Parsons be regarded as the founder of the field since he coined the term 'vocational guidance' (Herr, 2001), Parsons aimed to match the attributes required in particular jobs and personality traits of individuals. Similarly, in his typology theory, Holland suggested six categories of personality types as realistic, investigative, artistic, social, enterprising, and conventional and discusses the career fields that would fit the personality types. Holland argues that people can be grouped according to their personality types and that they can be happy and successful in environments that fit their personality types (Kuzgun, 2009). In his study, which is in line with the theories within this approach, Oğuz (2008) concludes that the most significant indicator of vocational maturity is self-efficacy. Whiston and Keller (2004) also suggest that there is a significant correlation between the vocational maturity scores and self-efficacy scores of the student participants of their study. These findings seem to support the correlation between the self-concept and the career choice of the individual.

As far as the theories of career development are concerned, it is seen that people in the 12-15 age group develop their self-concept, identify their personal interests and talents, and explore different career choices through role tryouts. In other words, the individual relates his or her own interests and skills to specific requirements of jobs, and continues exploration and tryouts. This individual, who according to Ginzberg is in the tentative stage and to Super in the exploration stage, is an adolescent. It is a known fact that in the adolescence the individual goes through a process of self-identity development as a result of his developing abstract thinking and cognitive skills. The individual that is described above is in the secondary school stage in Turkey. The exams he or she takes immediately after the secondary school determines the high school that he or she will be studying at, which is a significant step in terms of career choice. The individual is forced to make a choice of higher education while he or she is still in the exploration stage. An individual who has not yet set a career goal and who does not have the necessary awareness of career choice at the end of the secondary school is significantly challenged and makes random choices. Akbal1k (1991) suggests that almost half of the students in their third year in the secondary school are unaware of the need to make a career choice. In the studies conducted on vocational high school students in Turkey, it is concluded that the vocational maturity level of the students are rather low (Köküsoy, 2008; Özgan, 2006). Vocational maturity is related to interest-and-talent-based career choice, and a realistic perception of self-concept and self-efficacy. The finding that the individual who is placed in a higher education institution and who, therefore, has taken a huge step in the process of career choice has a low level of 
vocational maturity highlights the need to work on this issue in the secondary school period. Research has shown that group counseling programs has turned out to be effective in increasing students' vocational maturity levels (Ayas, Deniz and Kağan, 2010; Bacanl1, 1995,2005; Bal, 1998; Evren, 1999, 2005; İşgör and Sezer, 2008; Makro and Savickas, 1998; Uskaner, 1999) and in supporting the students in the process of making a career choice (Bozgeyikli, 2005; Kırdök, 2006; Symes, 1998). Zeren (1999) and Çoban (2005) have also found a significant correlation between receiving vocational counseling support and the level of vocational maturity. In the light of these findings, it seems very important that students' awareness of the significance of educational/vocational goal-setting be raised and that students be informed about vocations and higher education institutions.

The studies which were used for "vocational guidance" and defined as "the support given to young people to make a career choice that fits their capacity" by Parsons (Isaacson and Brown, 1997) during the early years when career choice and personality traits were tried to be linked together, have recently turned out to support life-long development theories and are now called career counseling and psychological counseling, which are considered to be provided for life (Herr and Cramer, 1996). Today, many service fields are considered to be related to career development and in educational institutions career counseling activities, including awarenessraising trainings, goal-setting practices, and so on, are carried out by school teachers and counseling units.

In the experimental process of the present study, two types of interventions will be used: creative drama and group counseling. Creative drama has become one of the prominent approaches recently since it does not aim to spoon-feed the information to the learner, but to ensure full retention of the information through keeping the learner cognitively and physically active at all times. According to Adigüzel (2001), the goal of creative drama is as follows: "The main goal of creative drama practices, which makes it possible for children, adolescents and young people to go back and forth between the real world and the imaginary world, is to raise individuals who are self-sufficient with a developed self-concept, able to interact with the environment, and highly articulate. Self-knowledge, which is considered one of the fundamentals of creative drama practices, is central to the present study since it is one of the basic attainments peculiar to adolescence and one of the main building blocks of the process of educational/vocational goal-setting. Group counseling is the group activities conducted by the psychological guidance units with students who share similar problems. According to Kuzgun (2002), the goals of group counseling are:

- To help the individual to find self-identity

- To help the individual to have a positive self-perception and to gain self-confidence

- To help to increase the individual's integrity in terms of consistency between his/her emotions, opinions, and behavior

- To provide the individual with the necessary environment to review his/her value judgments and their validity

- To show the individual the ways to communicate with other people by listening and understanding

- To provide the individual with the necessary opportunities to examine and question his relationships with authority figures such as parents and teachers, and with peers.

- Considering these goals, it can be said that group counseling method applies well to the aims of the present study. The research problem of this study is to determine whether or not the educational and vocational goal-setting information provided through group counseling and creative drama techniques causes a change in students' choice of career and educational goal-setting processes. 


\section{The Aim of the Study}

The general aim of this study is to evaluate the effectiveness of creative drama and group counseling methods in the decision-making processes of secondary school seventh grade students regarding their choice of career and educational/vocational goals. With this aim in mind, the study tests the following hypotheses:

- The students participating in the group counseling activities will be more efficient in making a career choice.

- The students participating in the creative drama sessions will be more efficient in making a career choice.

- The self-concept scores of the students participating in the group counseling group will increase.

- The self-concept scores of the students participating in creative drama sessions will increase.

- The definitions of the factors influencing the career choice process provided by the students participating in the creative drama sessions will become clearer.

- The short-term, medium-term and long-term goals of the students participating in the creative drama sessions will be clearer.

- The higher education goals of the students participating in the creative drama sessions will be clearer.

- The vocational goals of the students participating in the creative drama sessions will be clearer.

- The definitions of the factors influencing the career choice process provided by the students participating in the group counseling group will become clearer.

- The short-term, medium-term and long-term goals of the students participating in the group counseling group will be clearer.

- The higher education goals of the students participating in the group counseling group will be clearer.

- The vocational goals of the students participating in the group counseling group will be clearer.

\section{Methodology}

The research population of the present study consists of 45 randomly selected 7 th grade students studying at Şehitler İlköğretim Okulu in Mamak, Ankara during the 2009-2010 academic year. The creative drama program included a total of 15 students, ten female and five male, and the group counseling program included a total of 15 students, seven female and eight male. The control group also consisted of 15 students, seven female and eight male. The students who were in the creative drama, group counseling and control groups are randomly selected. Prior to the study, all of the participants were given MKVYÖ, KHDÖ and another questionnaire designed by the researcher as pre-test. Then, the creative drama and group counseling sessions were held and finally after the completion of the sessions, the same questionnaires used as pre-test were given to the students as post-test.

The data obtained from MKVYÖ and KHDÖ were analyzed through Wilcoxon signed rank test. This test is the nonparametric version of the one-sample t-test. Nonparametric tests are used when assumptions about the normal distribution in the population are not met. The signed rank test is a simple method based on making conclusions after estimating the differences between positive and negative values (Elliott, Woodward, 2007) and can be used when data are in equal interval scales. With all of these in mind, Wilcoxon signed rank test was used in the study. The questionnaire designed by the researcher was analyzed qualitatively through content analysis. The aim of qualitative inquiry is to answer what kind of meanings people attribute to events; that is, how they 
describe or interpret those events (Dey, 1993). The main aim of content analysis is providing a summary and interpretation of the findings to the reader (Yıldırım and Şimşek, 2003).

The limitation of the study is that the number of the students participating in each group was limited to 15 people in order to increase the effectiveness of creative drama and group counseling methods.

\section{Research Design}

This study is an experimental study which aims to determine the effects of the two training programs on the students' educational/vocational goal-setting behaviors. The study used a pre-test, post-test, and control group design.

\section{Data Collection Instruments}

In order to determine the effectiveness of creative drama and group counseling programs, this study used "Piers-Harris Children's Self-Concept Scale", "Career Decision Self-Efficacy Scale", and an open-ended questionnaire designed by the researcher.

Piers- Harris Children's Self-Concept Scale (KHDÖ): The scale was developed by Piers and Harris (1964) in order to determine students' feelings, opinions and attitudes about themselves (Öner, 2005). The standardization of the scale was based on a sample of 3rd to 12th grade students. The internal validity coefficient changes between 78- .93. The scale consists of six factors and 80 items. Although the order of the factors differed while adapting the scale to Turkish, the same factors were available in the Turkish scale at the end of the adaptation process.

Career Decision Self-Efficacy Scale (MKVYÖ): The scale was designed by Bozgeyikli (2004) in order to determine students' level of self-efficacy in making career decisions. The scale consists of a total of 27 items and three factors. These factors are titled as "Evaluating Individual and Vocational Attributes Properly", "Collecting Vocational Information", and "Making Realistic Plans".

The Questionnaire: The questionnaire was designed by the researcher in order to collect data from students about their knowledge of the concepts regarded significant in career choice. The questions in the questionnaire were "What is interest?", What is talent?", What is personality traits?", What are your short-term, medium-term, and long-term goals?", "What higher education institution would you like to go?", and "What occupations would you like to choose?".

\section{Data Collection}

Prior to the training programs, the students were given KHDÖ", "MKVYÖ", and the questionnaire as pre-test. Afterwards, the training sessions were held and immediately after the training a post-test was given to the students.

\section{Data Analysis}

To analyze the data collected in the study SPSS 13.0 program was used. The pre-test and post-test results of "MKVYÖ" and "KHDÖ" were analyzed using the Wilcoxon signed rank test, which is a nonparametric analysis method. 


\section{The Training}

The study aimed to determine the effectiveness of creative drama and group counseling methods in the process of educational/vocational goal setting. The reason why creative drama was preferred is that it keeps the participant active and thereby ensures full learning and retention, unlike oral communication methods. Group counseling was also preferred due to the fact that it is a method which is already used in school counseling units in general and mostly preferred in educational/vocational counseling practices in particular. The number, duration and the objectives of the training sessions in both creative drama and group counseling groups were the same so as to minimize the potential differences that might have occurred. The titles and objectives of the creative drama and group counseling sessions are given below:

Session 1: Introduction

- The student says the names of the group members.

- The student joins the group.

Session 2: Interests

- The student defines interest.

- The student realizes that everybody might have different interests.

- The student knows that interests affect choices.

Session 3: Talents

- The student says the names of talent domains.

- The student knows what talents each domain involves.

- The student becomes aware of his own talents.

- The student becomes aware of the importance of choosing fields that fit talents.

Session 4: Personality traits

- The student gives examples of personality traits.

- The student becomes aware of his/her own personality traits.

Session 5: Goal-setting

- The student becomes aware of the importance of goal setting.

- The student knows the effects of environment on goal setting.

- The student talks of the potential obstacles in daily life.

Session 6: Higher education institutions

- The student lists the names of higher education institutions.

- The student collects information about higher education institutions.

Session 7: Vocations

- The student becomes aware of the factors influencing one's choice of career.

- The student learns about various vocations. 


\section{Findings}

This section presents the results of the data obtained from MKVYÖ and KHDÖ, and the findings of the questionnaire. The quantitative data were analyzed through Wilcoxon Signed Rank Test, and the qualitative data were analyzed through content analysis.

\section{The Findings of MKVYÖ}

As a result of Wilcoxon signed rank test results of MKVYÖ scores of the students in the creative drama group, there found to be a significant difference $(\alpha=0,05)$ between pre-test $(\bar{X}=114,33)$ and post-test $(\bar{X}=118,67)$ scores. This suggests that the students' levels of self efficacy in career decisions increased at the end of the creative drama and group counseling sessions. However, in the control group there was not found to be a significant difference at a $\alpha=0,05$ level between the pre-test ( $\bar{X}=117,93)$ and post-test $(\bar{X}=119,07)$ scores of the students.

\section{The Findings of KHDÖ}

As a result of Wilcoxon signed rank test results of KHDÖ scores of the students, there was not a significant difference at $\alpha=0,05$ level between the pre-test ( $\bar{X}=64,87$ ) and the post-test ( $\bar{X}=66,00)$ scores of the students in the creative drama group; between the pre-test $(\bar{X}=61,67)$ and post-test ( $\bar{X}=60,93$ ) scores of the students in the group counseling group; and the pre-test ( $\bar{X}=61,93$ ) and post-test ( $\bar{X}=65,13$ ) scores of the students in the control group. This suggests that after the treatments there was no significant difference in the self- perceptions of the students who participated in creative drama and group counseling sessions.

\section{The Results of the Content Analysis of the Questionnaire Data}

Table 1. The Results of the Content Analysis for the Question "What is interest?"

\begin{tabular}{cccccc}
\hline \multicolumn{2}{c}{ Creative Drama } & \multicolumn{2}{c}{ Group Counseling } & \multicolumn{2}{c}{ Control Group } \\
\hline Pre-test & Post-test & Pre-test & Post-test & Pre-test & Post-test \\
\hline Curiosity & Curiosity & Curiosity & Curiosity & Curiosity & Curiosity \\
\hline Desire & Desire & Desire & Desire & Desire & Desire \\
\hline $\begin{array}{c}\text { Liking / } \\
\text { Love }\end{array}$ & $\begin{array}{c}\text { Liking/ } \\
\text { Love }\end{array}$ & Talent & $----------~$ & $\begin{array}{c}\text { Liking/ } \\
\text { Love }\end{array}$ & $\begin{array}{c}\text { Liking/ } \\
\text { Love }\end{array}$ \\
\hline Other & Other & $\begin{array}{c}\text { Liking/ } \\
\text { Love }\end{array}$ & $\begin{array}{c}\text { Liking/ } \\
\text { Love }\end{array}$ & Other & Other \\
\hline & Other & Other & & \\
\hline
\end{tabular}

The pre-test and post-test answers of the students in the creative drama group to the questionnaire are categorized under titles such as "curiosity", "desire", "liking/love", and "other". As can be seen from the table, the students mostly defined interest through the concept of "curiosity" and the answers to the pre-test and posttest are found to be in parallel to each other. 
The pre-test answers of the students in the group counseling group are categorized under titles such as "curiosity", "desire", "talent", "liking/love", and "other". The "talent" category in the pre-test answers was not available in the post-test results. It is observed that the students mostly defined interest through the concept of "curiosity".

The pre-test and post-test answers of the students in the control group are categorized under titles such as "curiosity", "desire", "liking/love", and "other". As is seen in the table, the students mostly defined interest through the concept of "curiosity" and the answers to the pre-test and post-test are found to be in parallel to each other.

Table 2. The Results of the Content Analysis for the Question "What is Talent?"

\begin{tabular}{|c|c|c|c|c|c|}
\hline \multicolumn{2}{|c|}{ Creative Drama } & \multicolumn{2}{|c|}{ Group Counseling } & \multicolumn{2}{|c|}{ Control Group } \\
\hline Pre-test & Post-test & Pre-test & Post-test & Pre-test & Post-test \\
\hline $\begin{array}{l}\text { Being } \\
\text { capable }\end{array}$ & Being capable & $\begin{array}{l}\text { Being } \\
\text { capable }\end{array}$ & Being capable & $\begin{array}{l}\text { Being } \\
\text { capable }\end{array}$ & $\begin{array}{c}\text { Being } \\
\text { capable }\end{array}$ \\
\hline Success & ---------------- & Success & ---------------- & $\begin{array}{l}\text { Being } \\
\text { good / } \\
\text { Skill }\end{array}$ & $\begin{array}{c}\text { Being } \\
\text { good / } \\
\text { Skill }\end{array}$ \\
\hline $\begin{array}{l}\text { Being good } \\
\text { / Skill }\end{array}$ & $\begin{array}{l}\text { Being good / } \\
\text { Skill }\end{array}$ & $\begin{array}{l}\begin{array}{l}\text { Being } \\
\text { good/ }\end{array} \\
\text { Skill }\end{array}$ & $\begin{array}{l}\text { Being good / } \\
\text { Skill }\end{array}$ & Other & Other \\
\hline Other & Other & Other & Other & & \\
\hline $\begin{array}{l}\text { Being } \\
\text { capable }\end{array}$ & Being capable & $\begin{array}{l}\text { Being } \\
\text { capable }\end{array}$ & Being capable & $\begin{array}{l}\text { Being } \\
\text { capable }\end{array}$ & $\begin{array}{l}\text { Being } \\
\text { capable }\end{array}$ \\
\hline
\end{tabular}

The answers of the students participating in the creative drama group are categorized under titles such as "being capable", "success", "being good/skill", and "other". The results of the post-test provided the same categories except for the "success" category. It is seen that the majority of student answers fall into the category of "being capable".

The answers of the students participating in the group counseling group are categorized under titles such as "being capable", "success", "being good/skill", and "other". The results of the post-test provided the same categories except for the "success" category. It is seen that the majority of student answers fall into the category of "being capable".

The answers of the students in the control group are categorized under titles such as "being capable", "being good/skill", and "other". As is seen in the table, the majority of student answers fall into the category of "being good/skill". 
Table 3. The Results of the Content Analysis for the Question "What is Personality Traits?

\begin{tabular}{|c|c|c|c|c|c|}
\hline \multicolumn{2}{|c|}{ Creative Drama } & \multicolumn{2}{|c|}{ Group Counseling } & \multicolumn{2}{|c|}{ Control Group } \\
\hline Pre-test & Post-test & Pre-test & Post-test & Pre-test & Post-test \\
\hline $\begin{array}{c}\text { Personal } \\
\text { Traits }\end{array}$ & Personal Traits & $\begin{array}{c}\text { Personal } \\
\text { Traits }\end{array}$ & $\begin{array}{c}\text { Personal } \\
\text { Traits }\end{array}$ & $\begin{array}{c}\text { Personal } \\
\text { Traits }\end{array}$ & $\begin{array}{c}\text { Personal } \\
\text { Traits }\end{array}$ \\
\hline Behavior & Behavior & Other & Other & Other & Other \\
\hline Internal traits & -------------- & & Behavior & & Behavior \\
\hline Other & Other & & & & \\
\hline
\end{tabular}

The pre-test answers of the students in the creative drama group are categorized under titles such as "internal traits", "behavior", and "other". The "internal traits" category was not available in the post-test results, but an additional category, "personal traits" was formed in the post-test and this category was found to have the highest frequency.

The answers of the students in the group counseling group was categorized as "personal traits" and "other". The post-test yielded an additional category, "behavior". The category with the highest frequency in both the pre-test and post-test was found to be "personal traits".

The answers of the students in the control group are categorized as "personal traits" and "other". The majority of student answers fall into the "personal traits" category. The results of the post-test yielded an additional category, "behavior"; however, the category with the highest frequency was "other".

Table 4. The Results of the Content Analysis for the Questions "What higher Education Institution Would You Like To Go?" and "What Occupations Would You Like To Choose?"

\begin{tabular}{|c|c|c|c|c|c|c|}
\hline \multirow[t]{2}{*}{ Groups } & \multicolumn{2}{|c|}{$\begin{array}{c}\text { Higher education } \\
\text { institution and vocation } \\
\text { parallel }\end{array}$} & \multicolumn{2}{|c|}{$\begin{array}{l}\text { Higher education } \\
\text { institution and } \\
\text { vocation not parallel }\end{array}$} & \multicolumn{2}{|c|}{$\begin{array}{l}\text { Higher education } \\
\text { institution misstated }\end{array}$} \\
\hline & Pre-test & Post-test & Pre-test & Post-test & Pre-test & Post-test \\
\hline Creative Drama & 15 & 22 & 2 & 9 & 1 & 1 \\
\hline Group Counseling & 10 & 18 & 10 & 9 & & 2 \\
\hline Control & 11 & 10 & 8 & 9 & 1 & 2 \\
\hline
\end{tabular}


According to the pre-test answers of the students in the creative drama group, there are parallels between 15 higher education institutions and vocations; one of the higher education institutions is misstated, and there was found to be no parallels between two of the selected higher education institutions and vocations. In the posttest answers, however, it is seen that there are parallels between vocations and 22 higher education institutions stated by the students, that one of the higher education institutions is misstated, and that there are no parallels between vocations and nine higher education institutions the students selected.

According to the pre-test answers of the students in the group counseling group, there are parallels between ten higher education institutions and vocations, while there seems to be no parallels between vocations and the ten higher education institutions the students selected. In the post-test answers, it is seen that there are parallels between vocations and 18 higher education institutions, that two of the higher education institutions are misstated, and that there are no parallels between vocations and nine higher education institutions the students selected.

The answers of the students in the control group suggest that there are parallels between vocations and 11 higher education institutions; one of the higher education institutions is misstated and there seems to be no parallels between vocations and eight that two of the higher education institutions selected by the students. According to the post-test answers, there are parallels between vocations and ten higher education institutions; two of the higher education institutions are misstated, and that there are no parallels between vocations and nine higher education institutions the students selected.

\section{Conclusion and Suggestions}

Research has proven that educational/vocational counseling practices are effective in and contribute positively to students' process of career choice (Ayas, Deniz and Kağan, 2010; Bacanl1, 1995,2005; Bal, 1998; Bozgeyikli,2005; Evren, 1999; İş̧ör and Sezer, 2008; Kırdök, 2006; Makro and Savickas, 1998; Symes, 1998; Uskaner, 1999). This study has shown that creative drama and group counseling sessions are effective in increasing students' self-efficacy in career decision. This result is consistent with Bozgeyikli's (2008) study, which focused on the effects of vocational group counseling on the career decision self-efficacy levels of eighth grade secondary school students. Bozgeyikli's study concluded that the self-efficacy levels of the eighth graders in career decision increased as a result of the experimental treatment.

Another result of the present study is that creative drama and group counseling practices are not effective in changing students' self-concepts. Self-concept is the answer to the most fundamental question, "Who am I?", an individual asks of himself or herself during adolescence. This individual, who is going through several physical, social and psychological changes, forms a self-concept by defining himself or herself in every field of life. This study implemented programs intended to increase self-efficacy in making educational/vocational decisions. Regarding this aim, it can be concluded that the implemented programs were insufficient to address the physical, social, and psychological changes and challenges the students were going through and to change their self-concepts. This aim seems to have been realized in Cerrahoğlu's (2002) study on social skills training, which intended to increase the concept of self alone.

As for the qualitative results of the present study, it was found that the students' definitions of the concepts introduced during the programs such as interest, talent, and personality were closer in the post-test answers to the dictionary definitions than in the pre-test answers. However, with regard to the correlations between short-term, medium-term, and long-term goal setting and the parallels between vocations and higher education institutions, the pre-test and post-test answers were observed to be consistent with each other. This result suggests that 
students should be given more support in goal setting. It is obvious that the students need more structured trainings intended to familiarize them with higher education institutions and vocations. Therefore, it can be suggested that further studies could especially focus on these issues.

It can be concluded from the present study that self-efficacy perceptions of the students regarding their educational/vocational goal setting abilities have increased. Therefore, it can be suggested that both the creative drama and the group counseling programs implemented in this study can be used in schools in order to increase students' self-efficacy in goal setting. 